\title{
CERES-Maize model-based simulation of climate change impacts on maize yields and potential adaptive measures in Heilongjiang Province, China
}

\author{
Yumei Lin, ${ }^{\mathrm{a}, \mathrm{b}}$ Wenxiang $\mathrm{Wu}^{\mathrm{a}}{ }^{*}$ and Quansheng $\mathrm{Ge}^{\mathrm{a}}$
}

\begin{abstract}
BACKGROUND: Climate change would cause negative impacts on future agricultural production and food security. Adaptive measures should be taken to mitigate the adverse effects. The objectives of this study were to simulate the potential effects of climate change on maize yields in Heilongjiang Province and to evaluate two selected typical household-level autonomous adaptive measures (cultivar changes and planting time adjustments) for mitigating the risks of climate change based on the CERES-Maize model.

RESULTS: The results showed that flowering duration and maturity duration of maize would be shortened in the future climate

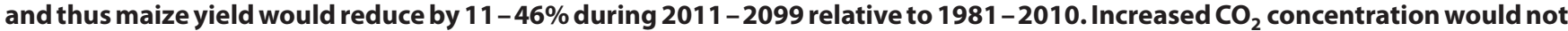
benefit maize production significantly. However, substituting local cultivars with later-maturing ones and delaying the planting date could increase yields as the climate changes.

CONCLUSION: The results provide insight regarding the likely impacts of climate change on maize yields and the efficacy of selected adaptive measures by presenting evidence-based implications and mitigation strategies for the potential negative impacts of future climate change.

(c) 2014 Society of Chemical Industry
\end{abstract}

Keywords: climate change impacts; adaptive measures; CERES-Maize model; Heilongjiang Province

\section{INTRODUCTION}

Agriculture is one of the most sensitive systems to climate change. ${ }^{1-3}$ Climate change, especially increases in atmospheric carbon dioxide $\left(\mathrm{CO}_{2}\right)$ concentrations, will result in increasing global temperatures and change current rainfall patterns. These changes could cause direct and indirect consequences for future agricultural production and food security. ${ }^{4-7}$ Considering the socio-economic importance of agriculture and food security, it is essential to assess how future climate change will affect crop yields. Adaptation is an important factor that will shape the severity of the impacts of climate change on food production in the future. , $^{8}$ Thus the relative potential of adaptation strategies should be developed and evaluated for coping with climate risk.

In China, maize is grown as a staple grain crop and fodder and an industrial raw material owing to its large production potential. In 2012 the total maize production and planting area in China were 205.6 million tons and 35.0 million hectares respectively. ${ }^{10}$ Northeast China (NEC), where the famous Golden Maize Belt of China is located, is an important commodity grain production base accounting for almost one-third of the nation's total maize production and planting area. As a geographical part of NEC, Heilongjiang Province accounted for $41.9 \%$ of the total maize production in NEC and $14.0 \%$ of that in China in $2012 .{ }^{10}$ Thus maize here plays an important role in the regional food security. Similarly to other crops, maize growth and development are very sensitive to climate change. ${ }^{11,12}$ Therefore it is important to understand how maize production will be affected by climate change in Heilongjiang Province and which adaptive measures should be considered to mitigate the possible negative impacts or to benefit crop production under climate change.

Various methods have been used to explore the interactions between climate change and crop production and to assess adaptation measures. Physically based, plot-specific crop models, whose input parameters have physical meaning and represent the environmental and varietal variability, have been widely used to explore the potential impacts of climate change on food production and to evaluate adaptation options. ${ }^{13}$ Many researchers have combined point-based maize models with climate data that were derived from General Circulation Models (GCMs) or Regional Circulation Models (RCMs) to assess the potential impacts of

\footnotetext{
Correspondence to: Wenxiang Wu, Institute of Geographical Sciences and Natural Resources Research, Chinese Academy of Sciences, Beijing 100101, China.E-mail:wuwx@igsnrr.ac.cn

a Institute of Geographical Sciences and Natural Resources Research, Chinese Academy of Sciences, Beijing 100101, China

b University of Chinese Academy of Sciences, Beijing 100049, China
} 
climate change on maize production. ${ }^{4,14-17}$ The Decision Support System for Agrotechnology Transfer (DSSAT) is a comprehensive decision support system ${ }^{18}$ that includes the CERES-Maize (Crop-Environment Resource Synthesis, Maize) model. ${ }^{19}$ The CERES-Maize model is one of the most popular process-based maize models and has been extensively employed to evaluate the effects of climate and managerial practices on maize production across the world. In addition, the CERES-Maize model has undergone rigorous evaluation across a wide range of different climates and soil conditions in China. ${ }^{17,20-25}$ Many researchers have used the CERES-Maize model to assess the potential responses of maize to expected climate changes in China. Among these researchers, Wang and $\mathrm{Lin}^{26}$ and Lin et al. ${ }^{27}$ conducted earlier studies regarding the prediction of Chinese maize production based on the CERES-Maize model. Recently, Xiong et al. ${ }^{17}$ used the CERES-Maize model v3.5 with the regional climate model RCM-PRECIS to assess the effects of climate change on maize production in China under SRES (Special Report on Emission Scenarios) ${ }^{28}$ A2 and B2 scenarios. In addition, Guo et al. ${ }^{20}$ used the CERES-Maize model v4.0 with the HadCM3 global climate model to explore the effects of climate change on maize yields and water use efficiencies across the North China Plain under the SRES B2A scenario. Tao and Zhang ${ }^{22}$ used the CERES-Maize model v4.0 to simulate maize production for representative stations in China with global mean temperature increases of 1,2 and $3^{\circ} \mathrm{C}$ respectively.

However, few studies assessed and quantified the effectiveness of different adaptive strategies to provide farmers and policy-makers with explicit guidance. Furthermore, many of the previous studies were conducted at a national level ${ }^{22}$ or at a regional level ${ }^{20}$ with a very limited number of stations, which could not provide detailed simulations of the climate impacts and efficacy of adaptive measures for the large study region. In contrast, provincial-scale studies could provide higher-resolution data by using more study stations and thus enhance understanding of the climate impacts and adaptations. Wang et al. ${ }^{23}$ conducted a provincial-scale study using the CERES-Maize (DSSAT) v4.0 model and six SRES scenarios in Jilin, the neighboring province of Heilongjiang. Nevertheless, no systematic provincial-level simulation with the CERES-Maize model has been conducted in Heilongjiang Province, in which maize production would be more sensitive to climate change owing to its higher latitude.

In this study we assessed the potential impacts of climate change on yields of rain-fed maize during three periods, 2020s (2011-2040), 2050s (2041-2070) and 2080s (2071-2099), relative to the baseline (1981-2010) and evaluated the potential mediating efficiencies of two selected household-level autonomous adaptation options based on the recently developed CERES-Maize (DSSAT) v4.5 model and by using four Representative Concentration Pathways (RCPs) ${ }^{29,30}$ that were the state-of-the-art climate scenario set in Heilongjiang Province, China.

\section{MATERIALS AND METHODS \\ Study area and stations}

Heilongjiang Province $\left(43^{\circ} 25^{\prime}-53^{\circ} 33^{\prime} \mathrm{N}, 121^{\circ} 11^{\prime}-135^{\circ} 05^{\prime} \mathrm{E}\right)$ is located in the northernmost region of China at relatively high latitude and is one of the most sensitive regions to climate change. ${ }^{31}$ In the last 46 years, Heilongjiang Province has experienced a significant warming trend, with an annual temperature increase of $2.1^{\circ} \mathrm{C} .{ }^{32}$ Generally, the climate of this region is dominated by the continental-monsoon climate regime, with an annual precipitation that varies from 400 to $650 \mathrm{~mm}$. Most of the precipitation in this region occurs in the summer and autumn, which coincides with the growth period of maize and benefits its growth and development. ${ }^{31}$ The relative abundance of rainfall during the growing season ensures that precipitation is not the main restricting factor for maize growth. Instead, high temperatures and precipitation during the growing season, obvious seasonal differences, fertile soils that are rich in organic matter, and a vast alluvial flat plain make Heilongjiang Province one of the most important areas for commercial crop production in China.

Study stations here were selected from the Agrometeorological Experimental Stations (AESs) where maize growth and yield observations were available. In addition, these selected AESs met the following criteria: they (1) were located in primary maize production areas, (2) had representative maize cultivars that were cultivated for at least three years, (3) had good managerial records for the representative cultivars and (4) were located near weather stations to obtain weather observation records. Overall, we selected nine stations. Figure 1 shows the geographical locations of these stations, which follow an uneven distribution. Most of the stations are located in the southern vast plain, which corresponds to the main maize cultivation area.

\section{Climate scenario and climate model}

Climate scenarios reflect plausible future climate conditions that have been constructed to investigate the potential consequences of anthropogenic climate change and natural climate variability. ${ }^{33}$ Many earlier assessments of the impacts of climate change on crops were based on the Special Report on SRES scenarios that was used in the Third and the Fourth Assessment Report of the Intergovernmental Panel on Climate Change (IPCC). However, these SRES scenarios did not account for policy actions that would mitigate climate change..$^{29,34}$

Recently, the Fifth Assessment Report of the IPCC adopted a new scenario set that contains greenhouse gas (GHG) emissions and concentrations that are referred to as RCPs. These RCPs are named based on their relative radiative forcing $\left(\mathrm{W} \mathrm{m}^{-2}\right)$ at the end of the 21 st century as RCP2.6, RCP4.5, RCP6.0 and RCP8.5. RCP2.6 is a mitigation scenario leading to a very low forcing level, RCP4.5 and RCP6.0 are both medium stabilization scenarios and RCP8.5 is a scenario with very high GHG emissions. ${ }^{29,35}$ The corresponding $\mathrm{CO}_{2}$ emissions and concentrations of the four RCPs in the future are indicated in Figs 2(a) and 2(b) respectively.

The four RCPs, which cover a wide range of future emission and climate scenarios as illustrated in Fig. 2, were used as inputs for HadGEM2-ES ${ }^{36}$ to compute the climate projections in this study. HadGEM2-ES is a coupled atmospheric/ocean general circulation model that was used in the fifth phase of the Coupled Model Intercomparison Project (CMIP5). ${ }^{37}$ In view of the coarse spatial resolution and uncertainty of climate modelling, the HadGEM2-ES output data were downscaled to a $0.5^{\circ} \times 0.5^{\circ}$ grid with a daily temporal resolution and simultaneously bias-corrected using the quantile mapping method ${ }^{38}$ before they were used as inputs to run the crop model.

\section{CERES-Maize crop model}

The CERES-Maize model embedded in DSSAT was selected to simulate maize yield in Heilongjiang Province, since it is one of the oldest, most advanced and most widely used crop simulation models. ${ }^{39}$ This model is cultivar-specific and site-specific and operates on a daily time step. In addition, the model can simulate the development of roots and shoots, the growth and senescence of leaves and stems, biomass accumulation and the growth 


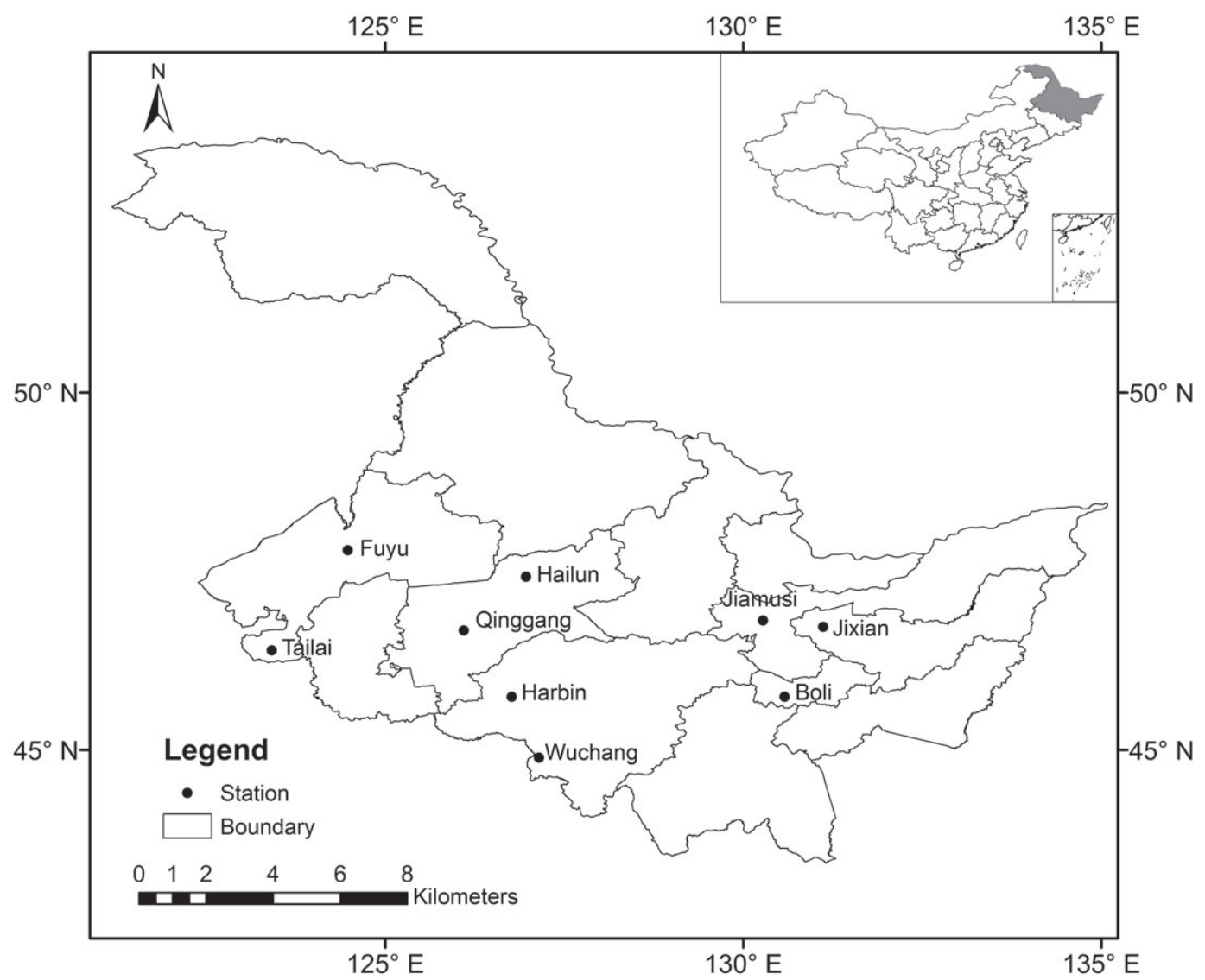

Figure 1. Geographical locations of selected maize stations in Heilongjiang Province.
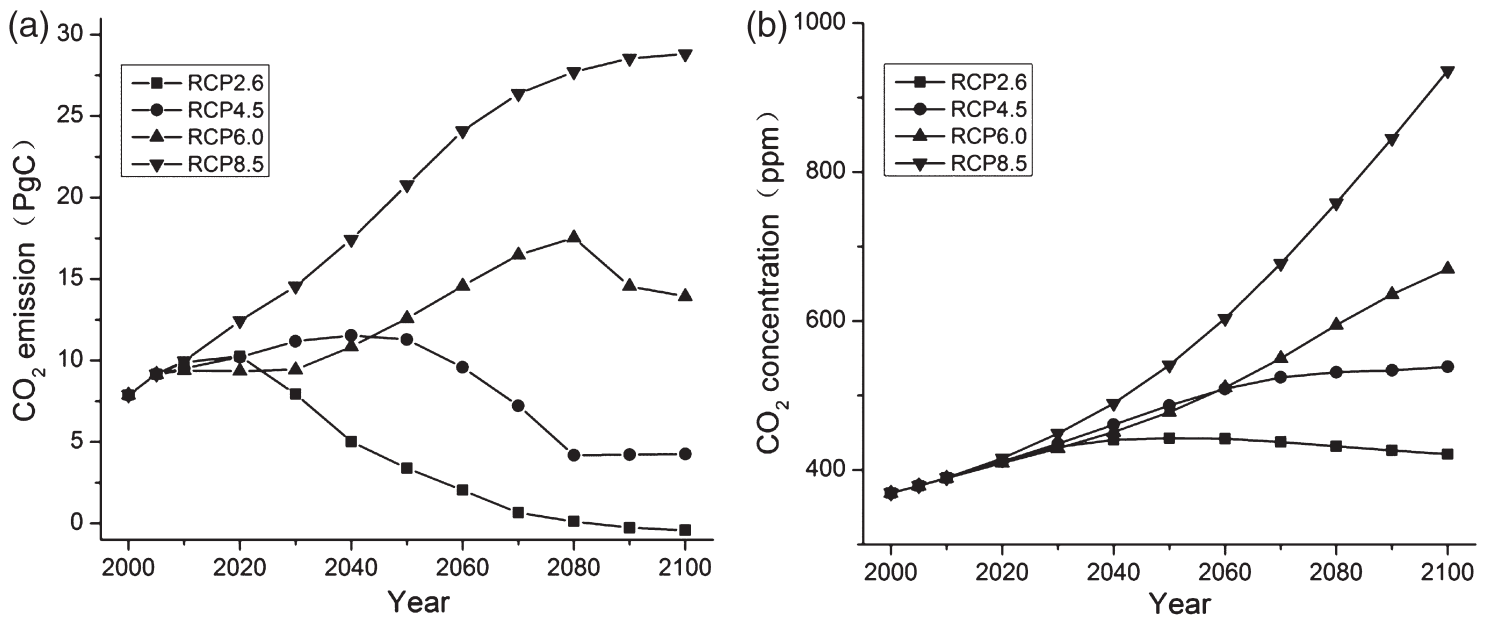

Figure 2. Global $\mathrm{CO}_{2}$ (a) emission and (b) concentration under different $\mathrm{RCP}$ scenarios.

of maize grains as a function of the weather and soil conditions, cropping management practices and cultivar characteristics (Fig. 3). ${ }^{18,19}$ Thus it can be used to simulate the impacts of weather, soil water, soil nitrogen dynamics and some management strategies on maize growth and yield. Since its release, ${ }^{19}$ the CERES-Maize model has been applied widely in different regions of the world at various scales from field to regional or national level. ${ }^{40}$

Here we used the most recent version CERES-Maize (DSSAT) v 4.5 to assess the potential impacts of future climate change and two adaptive measures on maize production in Heilongjiang Province.
Compared with the previous version CERES-Maize (DSSAT) v4.0, the newly developed one made some improvements in bug fixes and also owned new capabilities of modeling effects of organic matter on soil, reading atmospheric $\mathrm{CO}_{2}$ from external file, etc., all of which would elevate its performance for simulating crop growth and development. ${ }^{41}$

\section{Input data for CERES-Maize model}

The basic input data required by the CERES-Maize model include daily weather data, soil data, crop management data and 


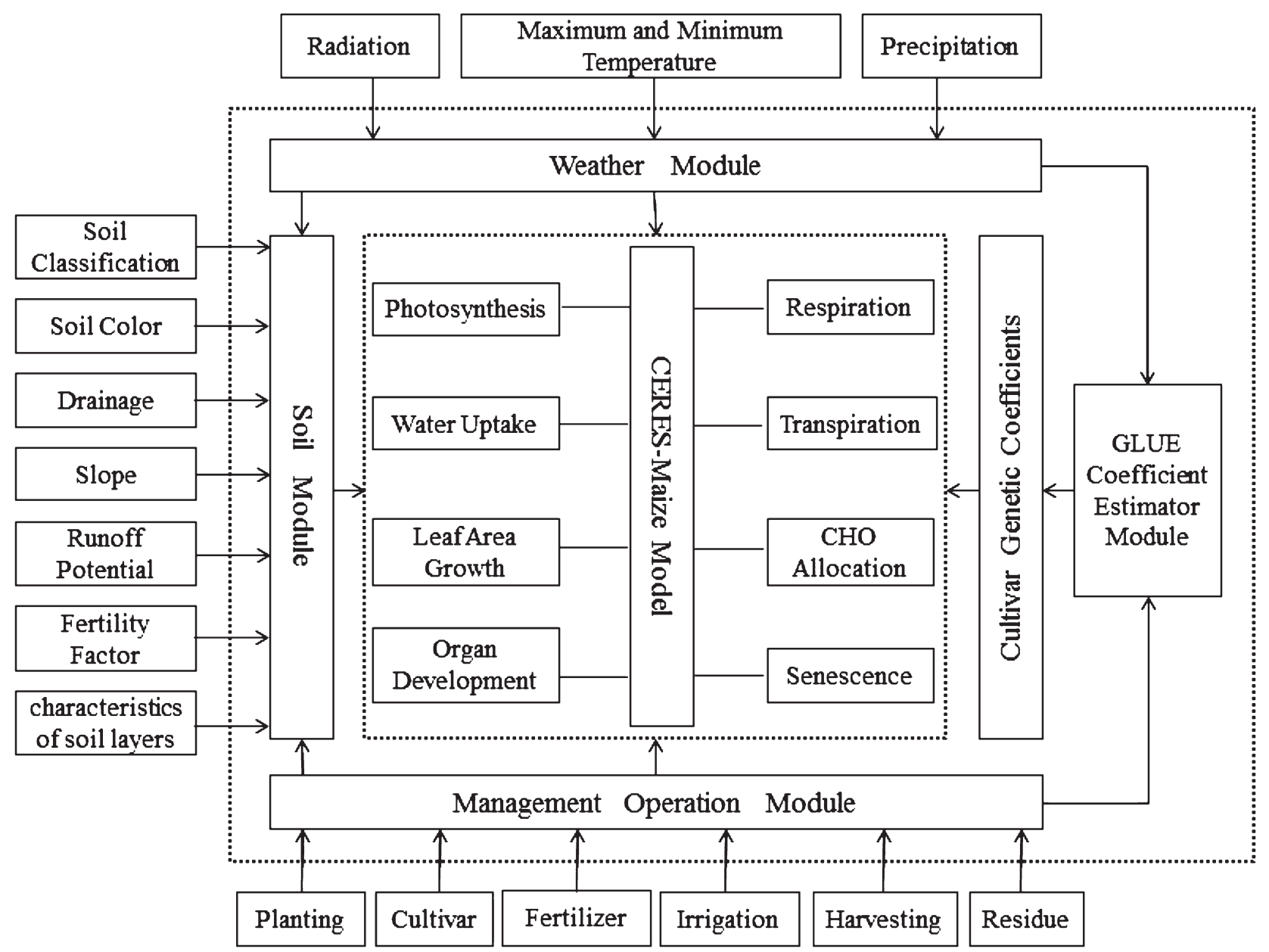

Figure 3. Overview of structure of CERES-Maize (DSSAT) v4.5 model. ${ }^{18}$

cultivar-specific genetic coefficients. Additional details regarding data requirement, data sources and data processing are provided below.

Weather data. The daily maximum and minimum air temperature, precipitation and solar radiation data at each station are used as the basic inputs for setting up weather files in the CERES-Maize model. The daily observed weather data (maximum and minimum air temperatures, precipitation and hours of sunshine) of the 1981-2010 baseline that was used for calibrating and validating the CERES-Maize model were obtained from the China Meteorological Data Sharing Service System (http://cdc.cma.gov.cn). The observed weather data for five selected stations (Fuyu, Harbin, Hailun, Jiamusi and Tailai) were collected from the local meteorological stations that were located at the same sites, while the weather data for the other four stations (Boli, Jixian, Qinggang, Wuchang) were filled using the data from the closest meteorological stations. The daily solar radiation data that are required by the model were not available. Thus the data were calculated at the station level using the Ångström equation, ${ }^{42}$ which is based on latitude and daily sunshine hours. The projected weather data for baseline, 2020s, 2050s and 2080s under the four different RCPs were derived from the GCM-HadGEM2-ES model. In addition, the weather data were bias-corrected and downscaled to a high resolution with a $0.5^{\circ} \times 0.5^{\circ}$ grid that was provided by the Inter-Sectoral Impact Model Intercomparison Project (ISI-MIP) of
Potsdam Institute for Climate Impact Research. Each of the study stations used the weather data from the nearest grid to simulate the maize yields of the baseline and future periods.

Soil data. The crop model requires soil data to describe soil characteristics for each study station. The required soil data include soil classification, color, slope, drainage class and the characteristics of each soil layer, which include soil mechanical composition, organic content, bulk density, pH value in water, cation exchange capacity and total nitrogen. These data were extracted from the Chinese Soil Genus Records. ${ }^{43}$

Crop observation and management data. The records of maize phenology, grain yields and management practices for the nine study stations between 1981 and 2009 were provided by the National Meteorological Centre of China, which collected these data from the local AESs. These records were used to define the required parameters (maize cultivar, row spacing, seeding density, seeding depth, fertilizer information, date of planting, date of harvest, etc.) of the CERES-Maize model. Based on the observed data of maize planting, flowering and maturity dates, the maize flowering duration (from planting to flowering) and maturity duration (from planting to maturity) were calculated. The phenology duration and grain yield data were used to calibrate and validate the CERES-Maize model. The records of maize grain yields, weeds, extreme climate events, plant diseases and insect 


\begin{tabular}{|c|c|c|}
\hline Coefficient & Description of genetic coefficient & Unit \\
\hline P1 & $\begin{array}{l}\text { Thermal time from seedling emergence to the } \\
\text { end of the juvenile phase (above a base } \\
\text { temperature of } 8^{\circ} \mathrm{C} \text { ) during which the plant } \\
\text { is not responsive to changes in photoperiod }\end{array}$ & ${ }^{\circ} \mathrm{C}$ days \\
\hline P2 & $\begin{array}{l}\text { Extent to which development is delayed for } \\
\text { each hour increase in photoperiod above } \\
\text { the longest photoperiod at which } \\
\text { development proceeds at a maximum rate } \\
\text { (which is considered to be } 12.5 \mathrm{~h} \text { ) }\end{array}$ & days \\
\hline P5 & $\begin{array}{l}\text { Thermal time from silking to physiological } \\
\text { maturity (expressed in degree days above a } \\
\text { base temperature of } 8^{\circ} \mathrm{C} \text { ) }\end{array}$ & ${ }^{\circ} \mathrm{C}$ days \\
\hline G2 & $\begin{array}{l}\text { Maximum possible number of kernels per } \\
\text { plant }\end{array}$ & - \\
\hline G3 & $\begin{array}{l}\text { Kernel-filling rate during the linear grain-filling } \\
\text { stage and under optimum conditions }\end{array}$ & $\mathrm{mg} \mathrm{day}^{-1}$ \\
\hline PHINT & $\begin{array}{l}\text { Phyllochron interval: the interval in thermal } \\
\text { time between successive leaf tip } \\
\text { appearances }\end{array}$ & ${ }^{\circ} \mathrm{C}$ days \\
\hline
\end{tabular}

pests were used to determine the representative maize cultivar for each study station.

Genetic coefficients. In the DSSAT model, the genetic coefficients are defined as sets of parameters that describe the interactions between crop genotype and environment. In addition, these coefficients characterize the differences in crop development, growth and yield among the cultivars. ${ }^{44}$

Six genetic coefficients are used by the CERES-Maize model to characterize or define one maize cultivar. Table 1 provides the definitions of the six genetic parameters. Four of the parameters (P1, P2, P5 and PHINT) control the timing of the phenological stages, while the other two parameters (G2 and G3) characterize the potential yield under optimal conditions.

Genetic coefficients can be directly measured in field experiments or estimated from observed data. ${ }^{45}$ However, the process of measuring genetic coefficients in the field is time-consuming and expensive and may be restricted to specific regions. In DSSAT, the GLUE (Generalized Likelihood Uncertainty Estimation) Coefficient Estimator module was designed to estimate genotype-specific coefficients for all included crop models, ${ }^{46}$ such as the CERES-Maize model. The main feature of this method is that it is relatively fast and cheap. Thus, in this study, the GLUE module was used with the multi-year observed cultivar data to determine the genetic coefficients of a certain maize cultivar.

\section{Calibration and validation of CERES-Maize model}

All crop models must be calibrated and validated for the environment of interest to obtain robust results. For model calibration, the genetic coefficients of each maize cultivar are determined by adjusting parameters until the simulated values agree well with the observed values. ${ }^{47}$ Model validation determines the ability of the calibrated model to simulate the characteristics of a separate data set. ${ }^{48}$

Before model calibration and validation, the representative maize cultivars should be selected. Not all maize cultivars should be used in the impact assessment and adaptive measure simulations. The selected cultivars must be continually cultivated for at least three years at the same site. In addition, the selected cultivars should have stable yields without any records of disease, weeds, extreme climate events or other stress conditions during the calibration and validation years.

The observed records for each representative cultivar from one year without environmental stress were selected for the genetic coefficient calibration using the GLUE Coefficient Estimator module. In addition, the records of two or three additional years were used for model validation. Information about the stations, representative cultivars and calibration and validation years is presented in Table 2.

The coincidence between the simulated and observed growth durations and grain yields could be measured using the normalized root mean square error (NRMSE), which is calculated by the equation

$$
\text { NRMSE }=\left[\sum_{i=1}^{n}\left(S_{i}-O_{i}\right) / n\right]^{1 / 2} \times\left(1 / \bar{O}_{i}\right)
$$

In addition, the degree that each simulated value deviates from the corresponding observed value can be evaluated by calculating the percentage of predicted deviation (PD) using the equation

$$
\mathrm{PD}_{i}=\left(S_{i}-O_{i}\right) / O_{i}
$$

Here $S_{i}$ and $O_{i}$ refer to the simulated and observed values for the studied variables respectively (e.g. maize flowering duration, maturity duration and grain yield), $\bar{O}_{i}$ is the mean of the observed values, $n$ is the number of comparisons and $i$ is each observation. The simulation is considered perfect when the NRMSE is less than $10 \%$, good if the NRMSE is greater than $10 \%$ and less than $20 \%$, fair if the NRMSE is greater than $20 \%$ and less than $30 \%$, and poor if the NRMSE is greater than $30 \% .{ }^{49}$ A negative deviation indicates an under-prediction, while a positive deviation indicates an over-prediction..$^{50}$ The closer the values of NRMSE and PD to zero, the better the model simulates the observed parameters. The simulated and observed data of maize flowering duration, maturity duration and grain yield were compared in this study.

\section{Model application}

To assess the impacts of future climate change on maize production, the commonly used 'dumb farmer' method ${ }^{51}$ was employed. This method assumes that all variables other than weather and atmospheric $\mathrm{CO}_{2}$ concentration, such as soil, cultivar and management practices, are held constant to simulate the impacts of climate change on maize production.

The assessment results of the climate change impacts were obtained by comparing the CERES-Maize model outputs over three periods (2020s, 2050s and 2080s) under four RCPs with the corresponding values of the baseline. To understand the impacts of increasing atmospheric $\mathrm{CO}_{2}$ concentrations on maize yields, we ran the crop model for all stations using the baseline $\mathrm{CO}_{2}$ concentration of $363 \mathrm{ppm}$. This concentration was derived from the NOAA Mauna Loa $\mathrm{CO}_{2}$ Database (http://co2now.org/). Next we ran the model using future $\mathrm{CO}_{2}$ concentrations under the four RCP scenarios in the 2080 s period. This period was used because the predicted $\mathrm{CO}_{2}$ concentrations were relative high compared with those of other periods among most RCP scenarios (Fig. 2(b) and Table 3).

To mitigate the negative impacts of climate change on maize production, two of the most commonly used household-level autonomous adaptation measures (replacing the local cultivars 
Table 2. Characteristics of sites selected for calibration and validation of crop model and projection of rice yield

\begin{tabular}{lccclll} 
Site & Longitude $(\mathrm{E})$ & Latitude $(\mathrm{N})$ & Altitude $(\mathrm{m})$ & Maize cultivar & \multicolumn{2}{l}{ Type of maturity } \\
Boli & $130^{\circ} 35^{\prime}$ & $45^{\circ} 45^{\prime}$ & 220.5 & 4 zao6 & Early & $2005^{*}, 2007-2009$ \\
Fuyu & $124^{\circ} 29^{\prime}$ & $47^{\circ} 48^{\prime}$ & 162.7 & Longdan1 & Late & $2000^{*}, 2001,2002$ \\
Harbin & $126^{\circ} 46^{\prime}$ & $45^{\circ} 45^{\prime}$ & 142.3 & 4 dan19-H & Late & $2003^{*}, 2004,2005$ \\
Hailun & $126^{\circ} 58^{\prime}$ & $47^{\circ} 26^{\prime}$ & 239.4 & Haiyu6 & Medium & $2005,2006,2007^{*}$ \\
Jiamusi & $130^{\circ} 17^{\prime}$ & $46^{\circ} 49^{\prime}$ & 81.2 & Dongnong248 & Mid-late & $2005,2006^{*}, 2008$ \\
Jixian & $131^{\circ} 07^{\prime}$ & $46^{\circ} 44^{\prime}$ & 102.3 & Hei221 & Medium & $2006^{*}, 2007,2008$ \\
Qinggang & $126^{\circ} 06^{\prime}$ & $46^{\circ} 41^{\prime}$ & 207.4 & 4 dan19-Q & Late & $2003^{*}, 2004,2007$ \\
Tailai & $123^{\circ} 25^{\prime}$ & $46^{\circ} 24^{\prime}$ & 150.5 & 4 dan19-T & Late & $2003,2006^{*}, 2008$ \\
Wuchang & $127^{\circ} 09^{\prime}$ & $44^{\circ} 54^{\prime}$ & 194.6 & Moji & Mid-late & $1999,2002,2003^{*}$
\end{tabular}

*The observed records of these years were used for calibrating the crop model.

Table 3. Projected changes in annual average temperature and precipitation in study area relative to baseline (1981-2010) and $\mathrm{CO}_{2} \mathrm{Concentration}$

\begin{tabular}{|c|c|c|c|c|c|c|c|c|c|}
\hline \multirow[b]{2}{*}{ Scenario } & \multicolumn{3}{|c|}{ Temperature increase $\left({ }^{\circ} \mathrm{C}\right)$} & \multicolumn{3}{|c|}{ Precipitation increase (\%) } & \multicolumn{3}{|c|}{$\mathrm{CO}_{2}(\mathrm{ppm})^{\mathrm{a}}$} \\
\hline & $2020 s$ & $2050 \mathrm{~s}$ & $2080 \mathrm{~s}$ & $2020 s$ & $2050 \mathrm{~s}$ & $2080 \mathrm{~s}$ & $2020 s$ & $2050 s$ & $2080 \mathrm{~s}$ \\
\hline RCP2.6 & 1.5 & 2.0 & 2.3 & 6.8 & 11.1 & 14.4 & 418 & 440 & 429 \\
\hline RCP4.5 & 1.5 & 3.0 & 3.8 & 8.2 & 8.7 & 12.9 & 424 & 495 & 523 \\
\hline RCP6.0 & 1.3 & 2.7 & 4.1 & 0.1 & 2.3 & 16.0 & 420 & 497 & 612 \\
\hline RCP8.5 & 1.5 & 4.1 & 7.0 & 7.2 & 12.9 & 23.7 & 436 & 578 & 804 \\
\hline
\end{tabular}

a Source: http://tntcat.iiasa.ac.at:8787/RcpDb/dsd?Action=htmlpage\&page=download.

and changing the planting dates) were selected to simulate their potential efficacy for offsetting climate risk.

With regard to switching the maize cultivars, we replaced the local early- or medium-maturing maize cultivars with late-maturing cultivars that have a longer growing season and relatively higher production. This new cultivar was introduced from another study station.

For shifting the planting date, we advanced the planting date in the simulations by 15, 10 and 5 days and compared the results with the current planting date for each station. In this way, we assessed how altering the planting date could increase maize yields. According to the results of the impact assessment mentioned above, maize production would suffer the most serious failure in the 2080 s period. Therefore this period was selected to simulate maize yields in this experiment. The simulated maize yields before and after adjusting the planting dates were compared with each other to evaluate the efficiency of this adaptive measure.

\section{RESULTS}

\section{Climate change scenarios of temperature and precipitation}

The average changes in temperature and precipitation of the study area under different RCP scenarios are shown in Table 3. It was obvious that the temperature would significantly increase with elevated $\mathrm{CO}_{2}$ concentrations in the future. The annual average temperature was projected to increase by $1.5,2.0$ and $2.3^{\circ} \mathrm{C}$ for the 2020s, 2050s and 2080s periods respectively relative to the baseline period under the RCP2.6 scenario. Under the RCP4.5 scenario, the annual average temperature was expected to increase by $1.5,3.0$ and $3.8^{\circ} \mathrm{C}$ in the $2020 \mathrm{~s}, 2050 \mathrm{~s}$ and 2080 s periods respectively. The trend of annual average temperature under the RCP6.0 scenario was similar to that under RCP4.5. However, the annual average temperature under the RCP8.5 scenario was the highest among all scenarios, with an increase of $7.0^{\circ} \mathrm{C}$ during the $2080 \mathrm{~s}$ period relative to the baseline period.

In addition, the annual average precipitation was projected to show an increasing trend with time under different scenarios. The annual precipitation would increase by $6.8,11.1$ and $14.4 \%$ in the 2020s, 2050s and 2080s periods respectively relative to the base period under the RCP2.6 scenario. However, under the RCP8.5 scenario, the annual average precipitation was expected to increase the most among all RCPs, with increases of 7.2, 12.9 and $23.7 \%$ in the 2020 s, 2050 s and 2080 s periods respectively.

\section{Performance of CERES-Maize model}

A comparative analysis showed that a close correspondence occurred between the observed and simulated flowering duration and the biological yield of all selected maize cultivars under the various agricultural management strategies and soil conditions (Fig. 4). The NRMSE was low for the two selected parameters. The lower NRMSE value (5.5\%) was obtained for flowering duration and the higher NRMSE value (10.8\%) was obtained for grain yield. According to the $\pm 15 \%$ PD criteria, the model accurately predicted both parameters (Fig. 4). After validating the CERES-Maize model, the ultimately defined genetic coefficients of all cultivars that were used for simulating the maize yield were obtained (Table 4).

\section{Climate change impact simulation}

Impacts on maize phenology

The flowering duration and maturity duration were two important phenological stages in the CERES-Maize model. The modeling results showed that the durations of flowering and maturity would be shortened by $3-27$ and 7-60 days respectively relative to the baseline conditions when considering the different cultivars, periods and RCP scenarios (Tables 5 and 6). The most serious 
(a)

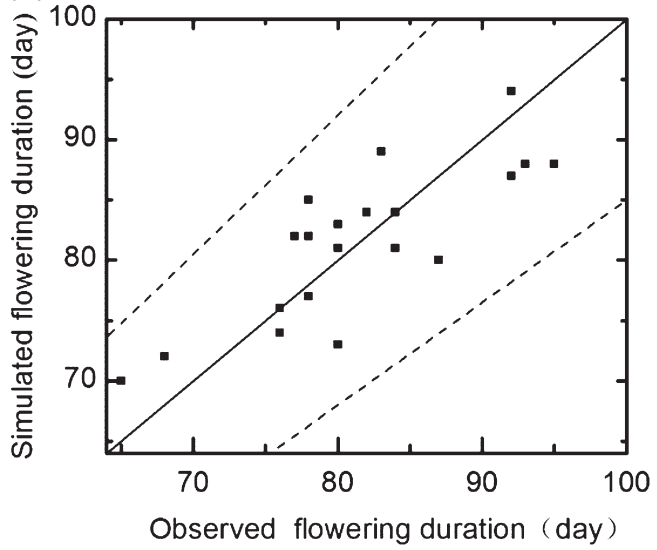

(b)

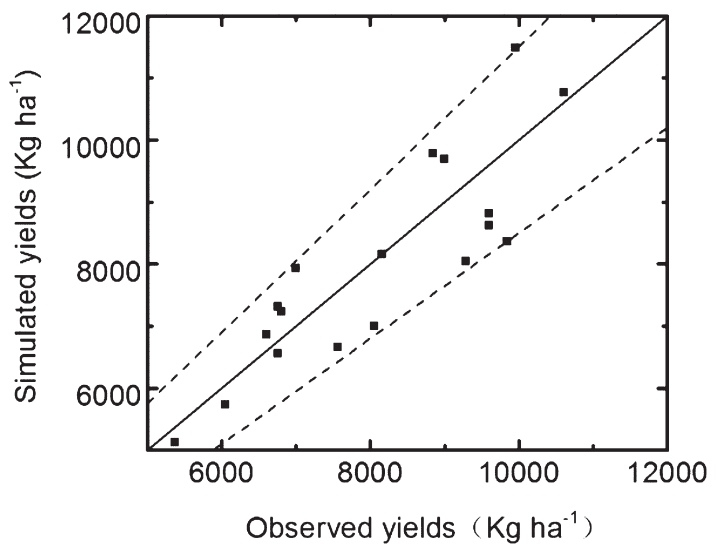

Figure 4. Comparison of simulated and observed (a) flowering durations and (b) yields. The full line is the 1:1 reference line and the broken lines show the percentage of PD with $\pm 15 \%$.

\begin{tabular}{|lcccccc|}
\hline \multicolumn{7}{|l|}{ Table 4. Calculated genetic coefficients of maize cultivars } \\
Cultivar & P1 & P2 & P5 & G2 & G3 & PHINT \\
\hline 4zao6 & 159 & 0.19 & 671 & 983 & 16.4 & 57.1 \\
Longdan1 & 240 & 0.93 & 708 & 475 & 12.4 & 46.1 \\
Haiyu6 & 161 & 0.67 & 712 & 553 & 13.8 & 46.8 \\
4dan19-H & 225 & 0.62 & 739 & 670 & 14.8 & 55.3 \\
Dongnong248 & 201 & 0.41 & 717 & 491 & 11.6 & 44.5 \\
Hei221 & 196 & 0.81 & 716 & 680 & 14.7 & 58.8 \\
4dan19-Q & 196 & 0.82 & 724 & 458 & 10.2 & 58.2 \\
4dan19-T & 254 & 0.20 & 723 & 772 & 15.0 & 45.7 \\
Moji & 209 & 0.85 & 708 & 625 & 13.3 & 40.6 \\
\hline
\end{tabular}

decreases in the flowering and maturity durations occurred under the RCP8.5 scenario, with decreases of 5-27 and 15-59 days respectively. This trend was the opposite for the RCP2.6 scenario. The shorter numbers of days for both durations under the RCP6.0 scenario were similar to the durations under the RCP4.5 scenario.

When considering the time series at all study sites, the average days of growing duration (from planting to maturity) decreased with time under all RCP scenarios except the RCP2.6 scenario. Under the RCP2.6 scenario, the shortest maize growing duration occurred during the 2050 s period.

In addition, the growing duration varied with the cultivars used at the different sites. The 4zao6 cultivar at the Boli station had the shortest maturity durations while the 4 dan 19-T cultivar at the Tailai station had the longest in all periods and RCP scenarios (Table 6). In addition, the Haiyu6 cultivar at the Hailun station had the largest decrease (38\%) in maturity duration relative to the current conditions under the RCP8.5 scenario during the 2080 s period.

\section{Impacts on maize yields}

By comparing the maize yield results under future climate conditions with those under the baseline, we obtained insight regarding the changes in maize yields induced by climate changes when the maize cultivars, soil conditions and management practices were held constant. The changes in average maize yields without incorporating the $\mathrm{CO}_{2}$ fertilization effects are presented in Fig. 5. The average maize yields decreased significantly $(11-46 \%)$ for all periods and RCP scenarios. Under all RCP scenarios, the decreasing yield trend continued with time. Thus the lowest decrease would occur in the 2020s period and the highest in the 2080s period, with decreases of $11-14$ and $17-46 \%$ respectively. The losses from the current maize yields were projected to be $11-17,10-32$, 14-34 and 14-46\% for the RCP2.6, RCP4.5, RCP6.0 and RCP8.5 scenarios respectively. Among all RCPs, the most serious impact of climate change on maize yield occurred under the RCP8.5 scenario, with decreases of 14, 24 and $46 \%$ for the 2020s, 2050 s and 2080 s respectively.

From the perspective of the stations, not all stations would face yield reductions in the future climate scenarios (Table 7). During the 2020s, the Fuyu, Jiamusi and Jixian stations would have $3-15 \%$ greater maize yields. The predicted grain yields ranged from $-61 \%$ (for the Haiyu6 cultivar at the Hailun station in the 2080 s under the RCP8.5 scenario) to $+15 \%$ (for the Longdan 1 cultivar at the Fuyu station in the 2020s under the RCP2.6 scenario) relative to the baseline conditions of the different cultivars, periods and scenarios (Table 7). The highest predicted maize yield $\left(8293 \mathrm{~kg} \mathrm{ha}^{-1}\right)$ occurred for the 4dan19-T cultivar at the Tailai station in the 2020s under the RCP 2.6 scenario. In addition, the lowest predicted maize yield $\left(2459 \mathrm{~kg} \mathrm{ha}^{-1}\right)$ occurred for the 4 dan $19-\mathrm{Q}$ cultivar at the Qinggang station in the 2080s under the RCP8.5 scenario (Table 7). Generally, early- and medium-maturing cultivars have lower maize grain yields. In addition, the long-season cultivars generally show smaller changes in grain yield relative to the medium- and short-season cultivars (Table 7).

When the $\mathrm{CO}_{2}$ fertilization effects were considered in the 2080s, the margin of the yield decrease was reduced by $1.6-3.7 \%$ owing to the increased yield that resulted from the increased atmospheric $\mathrm{CO}_{2}$ concentration (Table 8). In this case, the maize yields could increase by 959, 1958, 2207 and $2173 \mathrm{~kg} \mathrm{ha}^{-1}$ on average for the RCP2.6, RCP4.5, RCP6.0 and RCP8.5 scenarios respectively relative to the simulations that did not consider the $\mathrm{CO}_{2}$ fertilization effect.

\section{Adaptive measures simulation}

The results presented above indicated that the 4dan19-T cultivar at the Tailai station would have high grain yields owing to its long growth period in the future climate conditions (Tables 6 and 7). Thus we selected this cultivar to replace the shorter-season cultivars 4zao6 at the Boli station and Haiyu6 at the Hailun station, which were predicted to suffer higher yield reductions in the future 
Table 5. Changes in maize flowering duration (days) under future climate scenarios compared with baseline

\begin{tabular}{|c|c|c|c|c|c|c|c|c|c|c|c|c|c|}
\hline \multirow[b]{2}{*}{ Station } & \multirow[b]{2}{*}{$\mathrm{BS}^{\mathrm{a}}$} & \multicolumn{3}{|c|}{$\mathrm{RCP} 2.6$} & \multicolumn{3}{|c|}{$\mathrm{RCP} 4.5$} & \multicolumn{3}{|c|}{ RCP6.0 } & \multicolumn{3}{|c|}{ RCP8.5 } \\
\hline & & $2020 \mathrm{~s}$ & $2050 \mathrm{~s}$ & $2080 \mathrm{~s}$ & $2020 \mathrm{~s}$ & $2050 \mathrm{~s}$ & $2080 \mathrm{~s}$ & $2020 \mathrm{~s}$ & $2050 \mathrm{~s}$ & $2080 \mathrm{~s}$ & $2020 \mathrm{~s}$ & $2050 \mathrm{~s}$ & $2080 \mathrm{~s}$ \\
\hline Boli & 81 & -5 & -8 & -8 & -4 & -9 & -14 & -6 & -10 & -13 & -7 & -12 & -20 \\
\hline Fuyu & 92 & -4 & -9 & -7 & -4 & -11 & -15 & -5 & -10 & -15 & -5 & -13 & -21 \\
\hline Hailun & 81 & -5 & -9 & -8 & -5 & -10 & -14 & -5 & -10 & -14 & -6 & -13 & -20 \\
\hline Harbin & 90 & -6 & -10 & -9 & -6 & -12 & -16 & -3 & -9 & -19 & -7 & -14 & -27 \\
\hline Jiamusi & 78 & -3 & -7 & -7 & -3 & -8 & -13 & -3 & -8 & -13 & -5 & -10 & -18 \\
\hline Jixian & 89 & -5 & -9 & -9 & -5 & -11 & -15 & -5 & -11 & -15 & -7 & -13 & -22 \\
\hline Qinggang & 90 & -5 & -9 & -8 & -6 & -12 & -15 & -6 & -11 & -14 & -6 & -13 & -21 \\
\hline Tailai & 99 & -7 & -11 & -9 & -5 & -14 & -17 & -5 & -13 & -17 & -8 & -15 & -24 \\
\hline Wuchang & 91 & -6 & -10 & -8 & -6 & -11 & -15 & -7 & -12 & -15 & -7 & -14 & -22 \\
\hline
\end{tabular}

Table 6. Changes in maize maturity duration (days) under future climate scenarios compared with baseline

\begin{tabular}{|c|c|c|c|c|c|c|c|c|c|c|c|c|c|}
\hline \multirow[b]{2}{*}{ Station } & \multirow[b]{2}{*}{$\mathrm{BS}^{\mathrm{a}}$} & \multicolumn{3}{|c|}{$\mathrm{RCP} 2.6$} & \multicolumn{3}{|c|}{ RCP4.5 } & \multicolumn{3}{|c|}{ RCP6.0 } & \multicolumn{3}{|c|}{ RCP8.5 } \\
\hline & & $2020 \mathrm{~s}$ & $2050 \mathrm{~s}$ & $2080 \mathrm{~s}$ & $2020 s$ & $2050 \mathrm{~s}$ & $2080 \mathrm{~s}$ & $2020 \mathrm{~s}$ & $2050 \mathrm{~s}$ & $2080 s$ & $2020 \mathrm{~s}$ & $2050 \mathrm{~s}$ & $2080 \mathrm{~s}$ \\
\hline Boli & 151 & -20 & -29 & -26 & -19 & -34 & -43 & -18 & -34 & -43 & -26 & -38 & -54 \\
\hline Fuyu & 164 & -10 & -20 & -15 & -9 & -31 & -45 & -13 & -28 & -43 & -15 & -35 & -56 \\
\hline Hailun & 159 & -15 & -26 & -22 & -14 & -36 & -47 & -16 & -34 & -46 & -19 & -40 & -59 \\
\hline Harbin & 162 & -21 & -31 & -28 & -18 & -39 & -47 & -15 & -30 & -5 & -24 & -41 & -59 \\
\hline Jiamusi & 152 & -8 & -21 & -18 & -8 & -28 & -43 & -7 & -27 & -44 & -16 & -35 & -56 \\
\hline Jixian & 164 & -15 & -25 & -22 & -13 & -35 & -47 & -14 & -34 & -48 & -23 & -40 & -60 \\
\hline Qinggang & 161 & -19 & -29 & -26 & -16 & -38 & -46 & -18 & -35 & -45 & -22 & -41 & -57 \\
\hline Tailai & 169 & -13 & -22 & -18 & -10 & -36 & -45 & -14 & -33 & -45 & -17 & -35 & -57 \\
\hline Wuchang & 156 & -23 & -30 & -26 & -21 & -35 & -42 & -20 & -34 & -41 & -24 & -39 & -54 \\
\hline
\end{tabular}

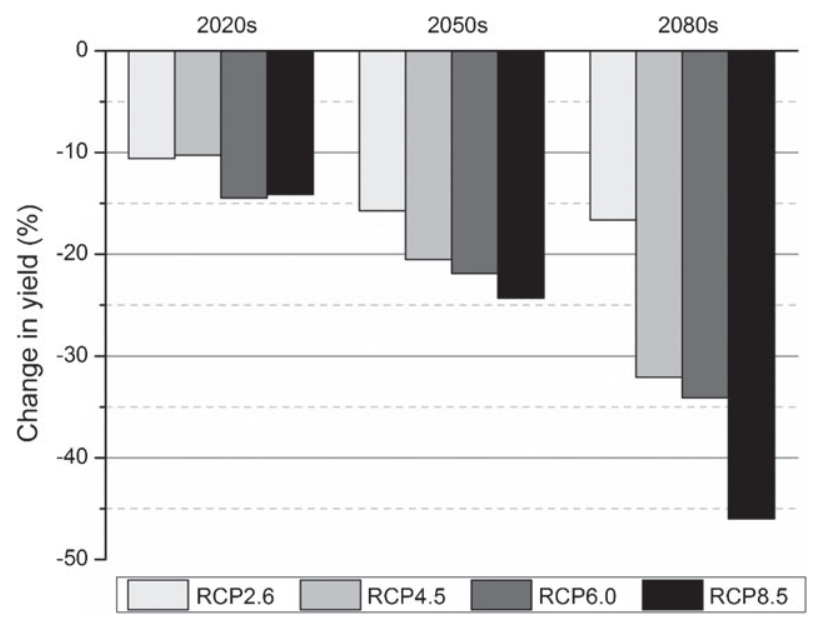

Figure 5. Changes in mean maize yields under future climate scenarios compared with baseline.

climate scenarios (Table 7). When the 4dan19-T cultivar was transplanted at the Boli station under the future scenarios, the maize yield increased by $35-39,28-42$ and $3-35 \%$ for the 2020 s, 2050 s and 2080 s periods respectively relative to the early-maturing cultivar 4zao6 (Fig. 6(a)). When the 4dan19-T cultivar was introduced at the Hailun station to replace the middle-maturing cultivar Haiyu6, the potential yield increases were $8-19,11-28$ and $6-23 \%$ for the 2020s, 2050s and 2080s periods respectively (Fig. 6(b)).
The simulation results from shifting the maize planting dates indicated that delaying the planting date by 5-15 days at most stations could result in yield increases of $1-27 \%$ relative to using the present planting dates in the 2080s period (Fig. 7). If the planting dates were advanced by 5-15 days, the maize yields would decrease by $4-16 \%$. Nevertheless, advancing the planting date did not always lead to lower maize yields. Advancing the planting date by 5-10 days at the Boli station under the RCP4.5, RCP6.0 and PCP8.5 scenarios resulted in a yield increase. In general, delaying the planting date by $5-15$ days increased the maize yields by an average of $6 \%$.

\section{DISCUSSION}

\section{Crop model validation}

The crop model accuracy is determined by the degree of goodness-of-fit between the observed and simulated values of specific parameters. According to the NRMSE description by Rinaldi et al., ${ }^{49}$ the calibrated CERES-Maize model showed robust ability to simulate the flowering durations (NRMSE $=5.5 \%$ ) and the grain yields (NRMSE $=10.8 \%$ ) in the model validation process. In addition, the low percentage of predicted deviations (PD $< \pm 15 \%)$ for all parameters confirmed that the CERES-Maize model performed well when simulating the phenological stages and the yields of the maize crop. Therefore this model is a reliable tool for climate change impact studies in Heilongjiang Province. 


\begin{tabular}{|c|c|c|c|c|c|c|c|c|c|c|c|c|c|}
\hline \multirow[b]{2}{*}{ Station } & \multirow[b]{2}{*}{$\mathrm{BS}^{\mathrm{a}}$} & \multicolumn{3}{|c|}{$\mathrm{RCP} 2.6$} & \multicolumn{3}{|c|}{ RCP4.5 } & \multicolumn{3}{|c|}{ RCP6.0 } & \multicolumn{3}{|c|}{ RCP8.5 } \\
\hline & & $2020 s$ & $2050 \mathrm{~s}$ & $2080 \mathrm{~s}$ & $2020 s$ & $2050 \mathrm{~s}$ & $2080 \mathrm{~s}$ & $2020 s$ & $2050 \mathrm{~s}$ & $2080 \mathrm{~s}$ & $2020 s$ & $2050 s$ & $2080 \mathrm{~s}$ \\
\hline Boli & 7513 & -13 & -16 & -14 & -4 & -9 & -14 & -6 & -10 & -13 & -7 & -12 & -20 \\
\hline Fuyu & 5484 & 11 & 9 & 15 & -4 & -11 & -15 & -5 & -10 & -15 & -5 & -13 & -21 \\
\hline Hailun & 6764 & -13 & -22 & -18 & -5 & -10 & -14 & -5 & -10 & -14 & -6 & -13 & -20 \\
\hline Harbin & 7239 & 0 & -1 & 3 & -6 & -12 & -16 & -3 & -9 & -19 & -7 & -14 & -27 \\
\hline Jiamusi & 5742 & 11 & 2 & 5 & -3 & -8 & -13 & -3 & -8 & -13 & -5 & -10 & -18 \\
\hline Jixian & 6509 & 5 & 4 & 7 & -5 & -11 & -15 & -5 & -11 & -15 & -7 & -13 & -22 \\
\hline Qinggang & 5800 & -12 & -23 & -13 & -6 & -12 & -15 & -6 & -11 & -14 & -6 & -13 & -21 \\
\hline Tailai & 7371 & -5 & 1 & 12 & -5 & -14 & -17 & -5 & -13 & -17 & -8 & -15 & -24 \\
\hline Wuchang & 7718 & -14 & -20 & -17 & -6 & -11 & -15 & -7 & -12 & -15 & -7 & -14 & -22 \\
\hline
\end{tabular}

Table 8. Changes in mean maize yield (\%) under future climate scenarios in 2080s with and without $\mathrm{CO}_{2}$ fertilization effect, and resulting values of fertilization effect

\begin{tabular}{lrrrr|}
$\mathrm{CO}_{2}$ fertilization effect & $\mathrm{RCP} 2.6$ & $\mathrm{RCP} 4.5$ & $\mathrm{RCP6.0}$ & $\mathrm{RCP} 8.5$ \\
\hline Without & -1.7 & -27.0 & -27.5 & -47.1 \\
With & -0.1 & -23.8 & -23.8 & -43.5 \\
Effect $^{\mathrm{a}}$ & 1.6 & 3.3 & 3.7 & 3.6 \\
\hline
\end{tabular}

${ }^{a}$ Obtained by calculating the difference between the results with and without $\mathrm{CO}_{2}$ fertilization effect.

\section{Impacts assessment}

All future climate scenarios indicated a general tendency toward shorter flowering and maturity durations for all maize cultivars. When the $\mathrm{CO}_{2}$ fertilization effects were not considered, the predicted grain yields of maize gradually decreased across all RCP scenarios. The projected decreasing trend of rain-fed maize production over time in this study agreed with those of Lin et al. ${ }^{27}$ and Xiong et al., ${ }^{17}$ who adopted SRES A2 and B2 scenarios, but the decreasing rate of maize yield was greater than them. For these studies, the most important causative factors for rain-fed crop yield reduction are increasing temperature and decreasing precipitation..$^{52,53}$ However, in view of the current sufficient water condition and the large precipitation increases that were projected by the HadGCM2-ES model under the RCP scenarios (Table 3), the water deficits may be slight or even not exist in many agricultural regions. Consequently, based on the applied scenarios, the increase in air temperature was the main factor that led to maize yield reductions in Heilongjiang Province. Elevated temperatures could accelerate the development of maize, resulting in earlier maturation and less time for the formation and accumulation of dry matter. ${ }^{54-56}$ Thus yield reductions would occur under the future warming climate conditions, while the decreasing rate of maize yield could be understood by the way that the temperature increase in Heilongjiang Province would be potentially greater than the national average level.

When the elevated $\mathrm{CO}_{2}$ concentration was considered in the simulation for the 2080s period, the $\mathrm{CO}_{2}$ fertilization effect on rain-fed maize was not as significant as that on irrigated rice and wheat simulated by Lin et al. ${ }^{27}$ based on the CERES family models. Additionally, the amplitude of rain-fed maize reduction decreased slightly more than that of Xiong et al. ${ }^{17}$ and Wang et al., ${ }^{23}$ in which the rain-fed maize may suffer water limitations. All these differences could be reasonably interpreted by two aspects. Firstly, photosynthesis in C3 plants (e.g. rice and wheat) usually increases in response to elevated $\mathrm{CO}_{2},{ }^{57}$ whereas photosynthesis of maize, a $\mathrm{C} 4$ plant, is almost $\mathrm{CO}_{2}$-saturated at current atmospheric $\mathrm{CO}_{2}$ concentrations owing to a C4-specific photosynthetic pathway, a $\mathrm{CO}_{2}$-concentrating pump. ${ }^{58}$ Therefore increased $\mathrm{CO}_{2}$ would directly generate great benefits on the photosynthesis of

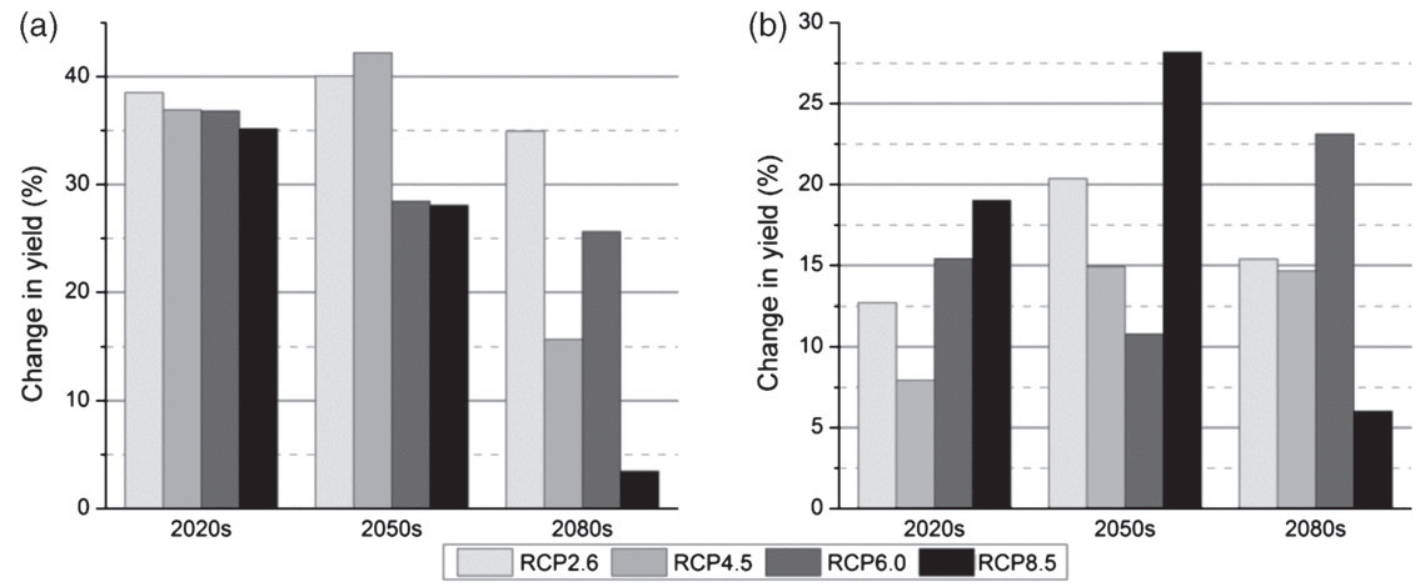

Figure 6. Changes in maize yields with 4 dan 19 cultivar at (a) Boli and (b) Hailun stations. 

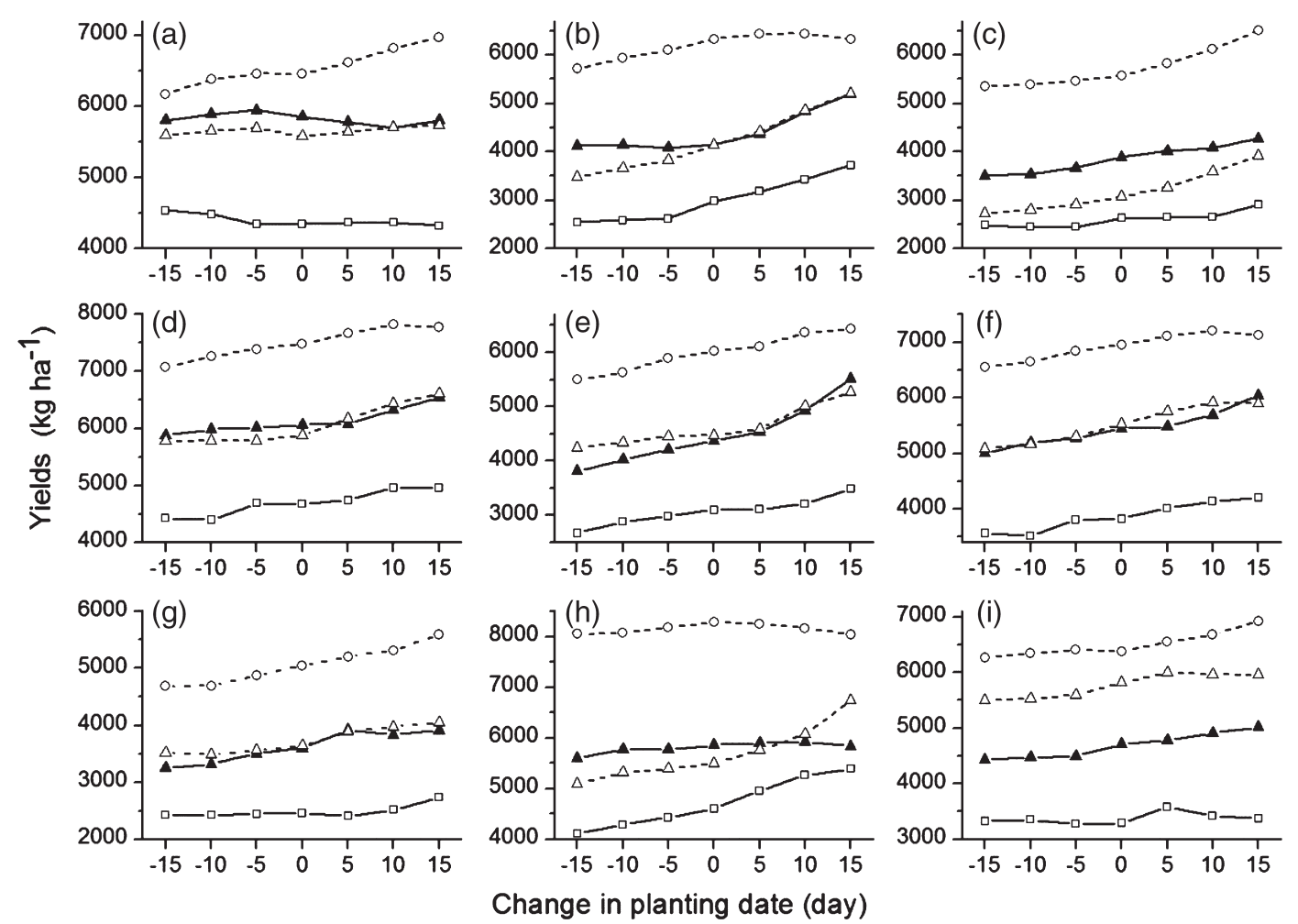

Change in planting date (day)

\begin{tabular}{|c|c|c|c|}
\hline$--\infty--$ RCP2.6 & $\multimap$ RCP4.5 & -- -- RCP6.0 & $\longrightarrow$ RCP8.5 \\
\hline
\end{tabular}

Figure 7. Maize yields on changed planting dates under different RCP scenarios at (a) Boli, (b) Fuyu, (c) Hailun, (d) Harbin, (e) Jiamusi, (f) Jixian, (g) Qinggang, (h) Tailai and (i) Wuchang stations.

rice and wheat, but little on that of maize. Secondly, elevated $\mathrm{CO}_{2}$ could decrease stomatal conductance, which may reduce transpiration in favor of delaying the onset of drought stress. ${ }^{59}$ It appears that the $\mathrm{CO}_{2}$ fertilization effect on maize would only be reflected when water is a limiting factor, because the $\mathrm{CO}_{2}$ effect on stomatal conductance may conserve soil water and increase drought tolerance. When both of the above aspects were considered, it was not difficult to understand that the $\mathrm{CO}_{2}$ fertilization effect on maize in this study was less than that on irrigated rice and wheat and that on maize under water stress condition. Thus the $\mathrm{CO}_{2}$ fertilization effect was too slight to offset the maize yield reduction at the end of the century in Heilongjiang Province.

Taken together, the maize production in Heilongjiang Province would suffer more negative effects from future climate change under RCP scenarios than the national average production under SRES scenarios. Therefore it was necessary to take adaptive measures to cope with the future climate conditions for ensuring food security.

\section{Adaptation evaluation}

Considering the apparent negative impact of climate change on maize yields, it is important to assess adaptive options in response to climate change, because efficient adaptive options could compensate some detrimental impacts. In this case, we found that, when the original cultivars were replaced by the late-maturing and high-yielding cultivar under the same climate and soil conditions, the maize yields increased significantly. This result potentially occurred because climate warming can extend the length of the potential growing season, ${ }^{31}$ and the late-maturing cultivar was able to use the heat from the warmer climate more efficiently. ${ }^{23}$ Therefore this cultivar had a longer growth season and thus had higher yields than the cultivar with early maturation. Wang et al. ${ }^{23}$ pointed out that the simulated maize production was greater when a maize cultivar with a longer growth period from southwest China was used to replace the local cultivar in Jilin Province. This adaptive measure was also true of other crops such as rice ${ }^{60}$ and wheat. $^{61}$ Although the late-maturing cultivar could increase yields, the increasing yield margin would decline with time owing to the high temperatures (Fig. 6). Thus more benefits will result from the development of new crop cultivars that are high-temperature-tolerant with higher thermal requirements. ${ }^{11}$

In addition, changing the planting dates is an another economic and feasible method for alleviating the adverse effects of climate change. ${ }^{11}$ Our simulation results indicated that, in general, delaying the planting dates of the maize cultivars by $5-15$ days would result in grain yield increases. This result potentially occurred because the delayed planting dates would allow the maize crop to avoid thermal stress during its key developmental stages. ${ }^{11,23,62}$ The changed trend of maize production with the changed planting dates was similar to that of Jin et al. ${ }^{63}$ However, Alexandrov and Hoogenboom ${ }^{61}$ reported that advancing the planting date of maize would increase maize yields in Athens. Additionally, Sultana et al. ${ }^{64}$ found that delaying planting dates would result in increased wheat yield in Pakistan. These results suggested that the proper change of planting dates for key developmental stages of crops to avoid thermal stress would vary with crop species, planting zones and future climate conditions.

It was thus evident that replacing the local cultivar by cultivars with longer growth periods and delaying the planting dates could be considered as two feasible adaptation strategies for reducing 
the negative impacts of climate change on maize production in Heilongjiang Province, and, based on the results of this study, changing cultivars may be more efficient than changing planting dates at the end of this century (Figs 6 and 7). In addition, Jin et al. ${ }^{63}$ stated that, by replacing cultivars and changing planting dates at the same time, maize production would gain more benefit than from adopting only one of the two adaptive measures. The efficiency of this integrative adaptation option needs further exploration in Heilongjiang Province.

\section{STUDY UNCERTAINTIES AND LIMITATIONS}

Estimates of the impacts of climate change on crop production that are based on crop models are plagued with uncertainties and limitations.

First, key uncertainties in crop production projections result from possible climate changes (GCM uncertainty). Different climate models can generate different climate scenarios. ${ }^{65}$ Since the findings in this study were based on bias-corrected HadGEM2-ES climate data, the crop production responses obtained using non-bias-corrected climate data or from other GCMs potentially may differ from our results. Second, although the CERES-Maize model has been widely employed, uncertainties and limitations can be derived from the crop model and its parametrizations. ${ }^{22}$ The model could not simulate the impacts of all of the important environmental and management factors on crop growth and production, including insect pests, weeds and diseases. Third, the CERES-Maize model characterizes a specific maize cultivar using six genetic coefficients. Thus the model could only describe the main properties of the cultivar rather than all its traits. The simplified coefficients would constrain the ability of the CERES-Maize model to simulate all maize cultivar characteristics. Finally, we adopted the 'dumb farmer' approach to assess the impacts of future climate changes. This means that changes in soil, cultivar and management practices and effects of technology improvements were not considered in these simulations owing to the lack of sufficient data and reasonable methodology. The implication of ignoring autonomous and planned adaptations in impact assessments would be an underestimation of the future maize yield and thus an overestimate of negative impacts of climate change.

\section{CONCLUSIONS}

Future climate change would negatively affect maize production in the main cultivated areas of Heilongjiang Province during this century under different RCP scenarios. The increased $\mathrm{CO}_{2}$ concentrations would not significantly increase the grain yields as the climate changed, because maize is a C4 crop and the precipitation would not be in deficit. Thus the increasing temperature would be the main climatic factor influencing maize production. However, switching the local maize cultivars and planting dates could mitigate the adverse impacts of elevated temperature. Replacing early- and mid-maturing cultivars with late-maturing cultivars could result in higher maize yields owing to the increased growth period. In addition, delaying the planting dates was an effective adaptation option for avoiding thermal stress during the key developmental stages of maize. Further research on the efficacy of breeding new crop cultivars and integrating the two adaptations simulated in this study is needed in order to mitigate the climate change impacts. These results could provide insights for famers and policy-makers regarding the likely impacts of climate change on maize production and the potential effective adaptations in Heilongjiang Province.

\section{ACKNOWLEDGEMENTS}

This research was jointly supported by the National Basic Research Program of China (973 Program) (Grant No. 2012CB955403), the CAS Strategic Priority Research Program (Grant No. XDA05130701) and the Natural Science Foundation of China (Grant No. 41172154). We also thank the China Meteorological Administration and the Inter-Sectoral Impact Model Intercomparison Project (ISI-MIP) of Potsdam Institute for Climate Impact Research for providing climate data.

\section{REFERENCES}

1 Meza FJ and Silva D, Dynamic adaptation of maize and wheat production to climate change. Clim Change 94:143-156 (2009).

2 Tao FL, Zhang Z and Yokozawa M, Dangerous levels of climate change for agricultural production in China. Reg Environ Change 11:S41-S48 (2011).

3 Zhou Y, Li N, Dong G and Wu W, Impact assessment of recent climate change on rice yields in the Heilongjiang Reclamation Area of north-east China. J Sci Food Agric 93:2698-2706 (2013).

4 Lee J, De Gryze S and Six J, Effect of climate change on field crop production in California's Central Valley. Clim Change 109:335-353 (2011).

5 Torriani DS, Calanca P, Schmid S, Beniston M and Fuhrer J, Potential effects of changes in mean climate and climate variability on the yield of winter and spring crops in Switzerland. Clim Res 34:59-69 (2007).

6 Trnka M, Dubrovsky M and Zalud Z, Climate change impacts and adaptation strategies in spring barley production in the Czech Republic. Clim Change 64:227-255 (2004).

7 Tubiello FN, Rosenzweig C, Goldberg RA, Jagtap S and Jones JW, Effects of climate change on US crop production: simulation results using two different GCM scenarios. Part I: Wheat, potato, maize, and citrus. Clim Res 20:259-270 (2002).

8 Intergovernmental Panel on Climate Change (IPCC), Climate Change 2007: the Physical Science Basis. Cambridge University Press, Cambridge (2007).

9 Lobell DB, Burke MB, Tebaldi C, Mastrandrea MD, Falcon WP and Naylor $\mathrm{RL}$, Prioritizing climate change adaptation needs for food security in 2030. Science 319:607-610 (2008).

10 Meng Q, Hou P, Lobell DB, Wang H, Cui Z, Zhang F, et al., The benefits of recent warming for maize production in high latitude China. Clim Change 122:341-349 (2014).

11 Tao F and Zhang Z, Adaptation of maize production to climate change in North China Plain: quantify the relative contributions of adaptation options. Eur J Agron 33:103-116 (2010).

12 Zhang T and Huang Y, Estimating the impacts of warming trends on wheat and maize in China from 1980 to 2008 based on county level data. Int J Climatol 33:699-708 (2013).

13 Timsina J and Humphreys E, Applications of CERES-Rice and CERES-Wheat in research, policy and climate change studies in Asia: a review. Int J Agric Res 1:202-225 (2006).

14 Dhakhwa GB, Campbell CL, LeDuc SK and Cooter EJ, Maize growth: assessing the effects of global warming and $\mathrm{CO}_{2}$ fertilization with crop models. Agric Forest Meteorol 87:253-272 (1997).

15 Farina R, Seddaiu G, Orsini R, Steglich E, Roggero PP and Francaviglia R, Soil carbon dynamics and crop productivity as influenced by climate change in a rainfed cereal system under contrasting tillage using EPIC. Soil Tillage Res 112:36-46 (2011).

16 Ruane AC, Cecil LD, Horton RM, Gordon R, McCollum R, Brown D, et al., Climate change impact uncertainties for maize in Panama: farm information, climate projections, and yield sensitivities. Agric Forest Meteorol 170:132-145 (2013).

17 Xiong W, Matthews R, Holman I, Lin E and Xu Y, Modelling China's potential maize production at regional scale under climate change. Clim Change 85:433-451 (2007).

18 Jones JW, Hoogenboom G, Porter C, Boote K, Batchelor W, Hunt L, et al., The DSSAT cropping system model. Eur J Agron 18:235-265 (2003). 
19 Jones CA and Kiniry JR, CERES-Maize: a Simulation Model of Maize Growth and Development. Texas A\&M University Press, College Station, TX (1986).

20 Guo R, Lin Z, Mo X and Yang C, Responses of crop yield and water use efficiency to climate change in the North China Plain. Agric Water Manag 97:1185-1194 (2010)

21 Liu H, Yang J, Drury C, Reynolds W, Tan C, Bai Y, et al., Using the DSSAT-CERES-Maize model to simulate crop yield and nitrogen cycling in fields under long-term continuous maize production. Nutr Cycl Agroecosyst 89:313-328 (2011).

22 Tao $\mathrm{F}$ and Zhang Z, Impacts of climate change as a function of global mean temperature: maize productivity and water use in China. Clim Change 105:409-432 (2011).

23 Wang M, Li Y, Ye W, Bornman JF and Yan X, Effects of climate change on maize production, and potential adaptation measures: a case study in Jilin Province, China. Clim Res 46:223-242 (2011).

$24 \mathrm{Wu}$ Y, Sakamoto $\mathrm{C}$ and Botner D, On the application of the CERES-Maize model to the North China Plain. Agric Forest Meteorol 49:9-22 (1989).

25 Ye L, Xiong W, Li Z, Yang P, Wu W, Yang G, et al., Climate change impact on China food security in 2050. Agron Sustain Dev 33:363-374 (2013).

26 Wang J and Lin E, The impacts of potential climate change and climate variability on simulated maize production in China. Water Air Soil Pollut 92:75-85 (1996).

27 Lin E, Xiong W, Ju H, Xu Y, Li Y, Bai L, et al., Climate change impacts on crop yield and quality with $\mathrm{CO}_{2}$ fertilization in China. Phil Trans $R \mathrm{Soc}$ B 360:2149-2154 (2005).

28 Intergovernmental Panel on Climate Change (IPCC), Special Report on Emissions Scenarios: a Special Report of Working Group III of the Intergovernmental Panel on Climate Change. Cambridge University Press, Cambridge (2000).

29 Moss RH, Edmonds JA, Hibbard KA, Manning MR, Rose SK, van Vuuren $D P$, et al., The next generation of scenarios for climate change research and assessment. Nature 463:747-756 (2010).

30 Intergovernmental Panel on Climate Change (IPCC), Climate Change 2013: the Physical Science Basis. Cambridge University Press, Cambridge (2013).

31 Liu Z, Yang X, Chen F and Wang E, The effects of past climate change on the northern limits of maize planting in Northeast China. Clim Change 117:891-902 (2012).

32 Yu $\mathrm{M}$, Xing J and Hongmin $\mathrm{Y}$, Air temperature change in Heilongjiang Province in recent 46 years. J Nat Disasters 18:158-164 (2009) (in Chinese).

33 Lee JW, Hong SY, Chang EC, Suh MS and Kang HS, Assessment of future climate change over East Asia due to the RCP scenarios downscaled by GRIMs-RMP. Clim Dyn 42:733-747 (2014).

34 Hasegawa T, Fujimori S, Shin Y, Takahashi K, Masui T and Tanaka A, Climate change impact and adaptation assessment on food consumption utilizing a new scenario framework. Environ Sci Technol 48:438-445 (2014).

35 Van Vuuren DP, Edmonds J, Kainuma M, Riahi K, Thomson A, Hibbard K, et al., The representative concentration pathways: an overview. Clim Change 109:5-31 (2011).

36 Collins W, Bellouin N, Doutriaux-Boucher M, Gedney N, Halloran P, Hinton $T$, et al., Development and evaluation of an Earth-system model - HadGEM2. Geosci Model Dev Discuss 4:997-1062 (2011).

37 Portmann FT, Doll P, Eisner S and Flörke M, Impact of climate change on renewable groundwater resources: assessing the benefits of avoided greenhouse gas emissions using selected CMIP5 climate projections. Environ Res Lett 8:024023 (2013).

38 Hempel S, Frieler K, Warszawski L, Schewe J and Piontek F, A trend-preserving bias correction - the ISI-MIP approach. Earth Syst Dyn Discuss 4:49-92 (2013).

39 Quiring SM and Legates DR, Application of CERES-Maize for within-season prediction of rainfed corn yields in Delaware, USA. Agric Forest Meteorol 148:964-975 (2008).

40 Lopez-Cedron FX, Boote KJ, Ruiz-Nogueira B and Sau F, Testing CERES-Maize versions to estimate maize production in a cool environment. Eur J Agron 23:89-102 (2005).

41 Hoogenboom G, Jones JW and Porter CH, Introduction to DSSAT v4.5, in Decision Support System for Agrotechnology Transfer Version 4.5. Volume 1: Overview, ed. by Hoogenboom G, Jones JW, Porter $\mathrm{CH}_{\text {, }}$ Wilkens PW, Boote KJ, Hunt LA, et al. University of Hawaii Press, Honolulu, HI, pp. 1-3 (2010).
42 Wang $\mathrm{E}, \mathrm{Yu} \mathrm{Q}, \mathrm{Wu} \mathrm{D}$ and Xia J, Climate, agricultural production and hydrological balance in the North China Plain. Int J Climatol 28:1959-1970 (2008).

43 National Soil Survey Office (NSSO), Chinese Soil Genus Records, Vol. 2. Chinese Agriculture Press, Beijing (1995) (in Chinese).

44 Hoogenboom G, Jones JW, Wilkens PW, Batchelor WD, Bowen WT, Hunt LA, et al., DSSAT version 3, vol. 2, in Crop Models, ed. by Tsuji GY, Uehara G and Balas S. University of Hawaii Press, Honolulu, HI, pp. 95-244 (1994).

45 Roman-Paoli E, Welch S and Vanderlip R, Comparing genetic coefficient estimation methods using the CERES-Maize model. Agric Syst 65:29-41 (2000).

46 He J, Jones JW, Graham WD and Dukes MD, Influence of likelihood function choice for estimating crop model parameters using the generalized likelihood uncertainty estimation method. Agric Syst 103:256-264 (2010).

47 Timsina J and Humphreys E, Performance of CERES-Rice and CERES-Wheat models in rice-wheat systems: a review. Agric Syst 90:5-31 (2006).

48 Xiong W, Holman I, Conway D, Lin E and Li Y, A crop model cross calibration for use in regional climate impacts studies. Ecol Model 213:365-380 (2008).

49 Rinaldi M, Losavio N and Flagella Z, Evaluation and application of the OILCROP-SUN model for sunflower in southern Italy. Agric Syst 78:17-30 (2003)

50 Soler CMT, Sentelhas PC and Hoogenboom G, Application of the CSM-CERES-Maize model for planting date evaluation and yield forecasting for maize grown off-season in a subtropical environment. Eur J Agron 27:165-177 (2007).

51 Intergovernmental Panel on Climate Change (IPCC), Climate Change 2001: Impacts, Adaptation, and Vulnerability. Cambridge University Press, Cambridge (2001).

52 El Maayar M, Singh B, André P, Bryant CR and Thouez JP, The effects of climatic change and $\mathrm{CO}_{2}$ fertilisation on agriculture in Québec. Agric Forest Meteorol 85:193-208 (1997).

53 Moradi R, Koocheki A and Mahallati MN, Adaptation of maize to climate change impacts in Iran. Mitig Adapt Strateg Global Change 19:1223-1238 (2014).

54 Abraha MG and Savage MJ, Potential impacts of climate change on the grain yield of maize for the midlands of KwaZulu-Natal, South Africa. Agric Ecosyst Environ 115:150-160 (2006).

55 Moradi R, Koocheki A, Mahallati MN and Mansoori H, Adaptation strategies for maize cultivation under climate change in Iran: irrigation and planting date management. Mitig Adapt Strateg Global Change 18:265-284 (2013).

56 Wolf $\mathrm{J}$ and Vandiepen CA, Effects of climate change on grain maize yield potential in the European Community. Clim Change 29:299-331 (1995).

57 Bazzaz FA, Garbutt K, Reekie EG and Williams WE, Using growth analysis to interpret competition between a C3 and a C4 annual under ambient and elevated $\mathrm{CO}_{2}$. Oecologia 79:223-235 (1989).

58 Ghannoum $\mathrm{O}, \mathrm{C}_{4}$ photosynthesis and water stress. Ann Bot 103:635-644 (2009).

59 Bunce JA, Carbon dioxide effects on stomatal responses to the environment and water use by crops under field conditions. Oecologia 140:1 - 10 (2004).

60 Krishnan P, Swain DK, Bhaskar BC, Nayak SK and Dash RN, Impact of elevated $\mathrm{CO}_{2}$ and temperature on rice yield and methods of adaptation as evaluated by crop simulation studies. Agric Ecosyst Environ 122:233-242 (2007).

61 Alexandrov VA and Hoogenboom G, Vulnerability and adaptation assessments of agricultural crops under climate change in the Southeastern USA. Theor Appl Climatol 67:45-63 (2000).

62 Lashkari A, Alizadeh A, Rezaei EE and Bannayan M, Mitigation of climate change impacts on maize productivity in northeast of Iran: a simulation study. Mitig Adapt Strateg Global Change 17:1 - 16 (2012).

63 Jin Z, Ge D, Gao L and Shi C, Food crop production strategies for adaptation to global climate change in the sampling zone of Eastern China - a modeling study. Sci Agric Sin 31:51-58 (1998) (in Chinese).

64 Sultana H, Ali N, Iqbal MM and Khan AM, Vulnerability and adaptability of wheat production in different climatic zones of Pakistan under climate change scenarios. Clim Change 94:123-142 (2009).

65 Yao F, Xu Y, Lin E, Yokozawa M and Zhang J, Assessing the impacts of climate change on rice yields in the main rice areas of China. Clim Change 80:395-409 (2007). 